2. Bousoño N. Un par de tequilazos para preparar la vista. prácticas de consumo de alcohol contemporáneo II. En: Libro de Resúmenes del VI Congreso Internacional de Investigación y Práctica Profesional en Psicología, XXI Jornadas de Investigación Décimo Encuentro de Investigadores en Psicología del MERCOSUR. Buenos Aires, Argentina. Facultad de Psicología, Universidad de Buenos Aires; 2014. p. 64-65.

3. Arango A, Vanegas CV. Efectos del consumo de alcohol vía vaginal en adolescentes en cuatro colegios de la ciudad de Medellín, Colombia. Rev Chil Obstet Ginecol. 2014;79(4):283-7.

4. Bousono N. Prácticas contemporáneas de consumo de alcohol: Una perspectiva psicoanalítica. Anu investig. 2012;19(2):57-62.

5. Monteiro Maristela G. Alcohol y salud pública en las Américas: un caso para la acción. Washington, D.C: OPS/OMS; 2007.

Correspondencia: Carlos Andrés Carrasco Farfán

Dirección: Los Pacaes A-29 Urb. San José. Ica, Perú.

Teléfono: (056) 969409456

Correo electrónico: candres.carrascof@gmail.com

\section{LA PLASTINACIÓN COMO MÉTODO DE CONSERVACIÓN DE TEJIDOS BIOLÓGICOS PARA DOCENCIA E INVESTIGACIÓN EN LA ANATOMÍA HUMANA}

\section{PLASTINATION AS A METHOD OF PRESERVATION OF BIOLOGICAL TISSUE FOR TEACHING AND RESEARCH IN HUMAN ANATOMY}

\section{Franklin Miranda Solis $1,2, a$}

Sr. Editor. En la formación de los médicos en nuestro país, la Anatomía es uno de los cursos más importantes de las ciencias básicas, la que se imparte en laboratorios especializados o anfiteatros. Estos lugares muchas veces son aulas adaptadas que no cuentan con un sistema de ventilación y menos con un sistema de

\footnotetext{
Facultad de Medicina, Universidad Nacional de San Antonio Abad del Cusco. Cusco, Perú.

2 Centro Nacional de Plastinación y Técnicas Anatómicas

aédico cirujano

Recibido: 22-08-15 Aprobado: 02-09-15
}

Citar como: Miranda Solis F. La plastinación como método de conservación de tejidos biológicos para docencia e investigación en la anatomía humana [carta]. Rev Peru Med Exp Salud Publica. 2015;32(4):819-20. conservación de órganos o cuerpos.

Antes de la invención del formaldehido como sustancia preservante los laboratorios implementaron técnicas y sustancias para la conservación de órganos y cadáveres tales como las resinas (aceites que retardaban el proceso de descomposición) (1). Estos agentes no llegan a conservar ciertas características como el color, volumen y otros aspectos que son importantes para el estudio y la investigación en esta área. Algunos agentes como el formaldehido presentan una elevada toxicidad, es así que en el año 2006 la Agencia Internacional para la Investigación sobre el Cáncer (IARC) lo clasificó como cancerígeno para los seres humanos ${ }^{(2)}$. Los laboratorios de Anatomía hacen uso de esta sustancia como agente fijador a

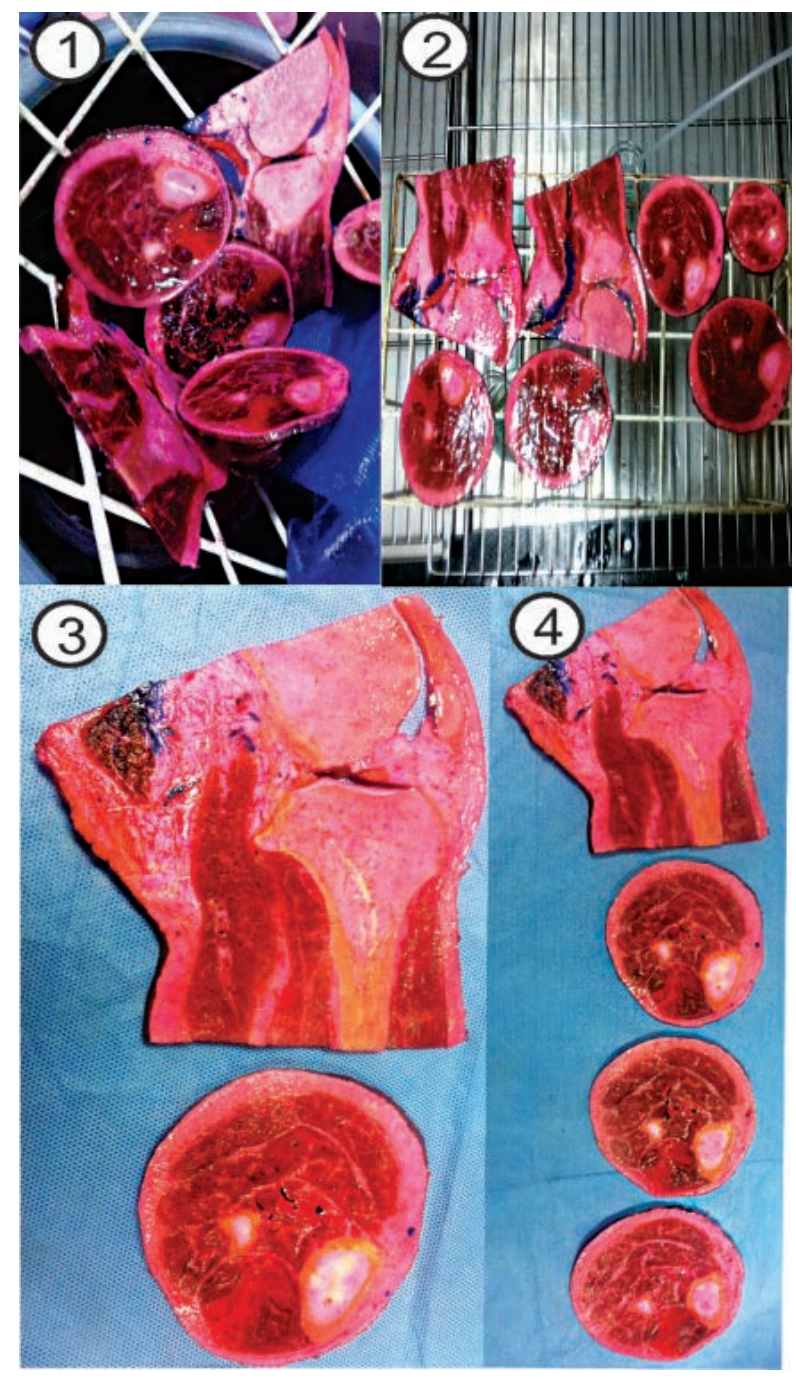

Figura 1. Se muestra secuencia de plastinación de corte de rodilla y tercio superior de pierna derecha: proceso final de impregnación forzada con silicona (1), para posteriormente pasar a cámara de curado con gas (2), quedando el producto final plastinado, libre de formol y de fácil manipulación (3 y 4). 
concentraciones muy altas (40\%) para la conservación de cadáveres.

Por tal motivo, se convirtió en necesidad realizar innovaciones e investigaciones en la conservación de los tejidos, órganos y cuerpos para obtener preparados anatómicos con mayor durabilidad y menos exposición a agentes cancerígenos, con menor riesgo para la salud de los alumnos y profesores. Fue por esta razón que en 1977 el doctor Gunther von Hagens creó la técnica de plastinación ${ }^{(3)}$.

En esta técnica, el agua y los lípidos de los tejidos son reemplazados por polímeros, estos luego son sometidos a un proceso de endurecimiento para dar como resultado una pieza seca, sin olor y perdurable; la técnica consta de cuatro pasos: a) fijación con formol al 5\%; b) deshidratación; c) impregnación forzada, y d) curado o endurecimiento de los polímeros. Las propiedades finales de la pieza dependen del tipo de polímero utilizado. La silicona proporciona piezas flexibles y aporta buenos resultados con requerimientos mínimos de equipamiento ${ }^{(4)}$.

Actualmente, el Centro Nacional de Plastinación de la Universidad Nacional de San Antonio Abad del Cusco viene desarrollando esta técnica con muy buenos resultados, obteniendo piezas anatómicas para la docencia y la investigación (Figura 1).

\section{REFERENCIAS BIBLIOGRÁFICAS}

1. Saeed M, Rufai AA, Elsayed SE. Mummification to plastination. Revisited. Saudi Med J 2001;22(11):956-9.

2. IARC Working Group on the Evaluation of Carcinogenic Risks to Humans. Formaldehyde, 2-butoxyethanol and 1-tertbutoxypropanol-2-ol. IARC Monographs Eval Carcinog Risks Hum. 2006;88:39-325.

3. Pashaei S. A brief review on the history, methods and applications of plastination. Int J Morphol 2010;28(4):1075-79.

4. von Hagens G, Tiedemann K, Kriz W. The current potential of plastination. Anat Embryol 1987;175(4):411-21

Correspondencia: Franklin Miranda Solis

Dirección: APV Minka A-8 San Sebastián. Cusco, Perú.

Teléfono: (084) 953749049

Correo:mdfranklinm@gmail.com,franklin.miranda@unsaac.edu.pe

\section{COMENTARIOS AL ARTÍCULO: PROGRAMA DE RESIDENTADO MÉDICO: PERCEPCIONES DE LOS MÉDICOS RESIDENTES EN HOSPITALES DE LIMA Y CALLAO}

\author{
COMMENTS TO THE ARTICLE: THE MEDICAL \\ RESIDENCY PROGRAM: PERCEPTIONS OF \\ RESIDENTS IN HOSPITALS OF LIMAAND \\ CALLAO
}

Cecilia Salgado-Lévano ${ }^{1, a}$

Sr. Editor. En el volumen 32(2) de su revista, Mini et al. (1) publicaron una investigación cuyo objetivo fue calificar la formación del programa de residentado médico desde las percepciones de los residentes. Si bien es un estudio importante, presenta debilidades metodológicas en el proceso de construcción y validación del instrumento, los cuales comprometen seriamente los resultados obtenidos.

En el artículo, los autores no especifican qué tipo de validez hallaron ni que método utilizaron para obtener los coeficientes de validez. Tampoco reportan el uso de la tabla de especificaciones que es un documento base para los procedimientos de validación por jueces ${ }^{(2)}$ donde típicamente se consignan la definición asumida del constructo, dimensiones, indicadores e ítems.

De acuerdo con la literatura científica, se deduce que al haber consultado a jueces expertos, buscaron hallar evidencias de la validez de contenido. La que se caracteriza porque al margen del análisis cualitativo de los expertos es imprescindible que estos aporten una valoración cuantitativa a los ítems; de no hacerlo, el solo hecho que opinen sobre la calidad y pertinencia de los ítems, (que determinen a qué dimensión corresponde o el grado de coherencia con la definición del dominio asumida), no aporta per se información para el proceso de validación, por lo que es necesario aplicar algunos de los métodos empíricos existentes para cuantificar este grado de acuerdo $^{(3)}$, algo que los autores no han reportado.

Los autores señalan que el instrumento se validó mediante una prueba piloto, lo que constituye otro error metodológico. El estudio piloto es un aspecto procedimental propio de las

\footnotetext{
1 Universidad San Ignacio de Loyola. Lima, Perú.

a Doctora en psicología

Recibido: 28-08-15 Aprobado: 02-09-15
}

Citar como: Salgado-Lévano C. Comentarios al artículo: programa de residentado médico: percepciones de los médicos residentes en hospitales de Lima y Callao [carta]. Rev Peru Med Exp Salud Publica. 2015;32(4):820-1. 